\title{
Clinical Results After Clear Lens Extraction (CLE) and Bilateral Implantation of Extended-Range- of-Vision Presbyopia-Correcting Intraocular Lenses (IOL) in 30 Patients
}

\author{
Igor Knezović*, Anđelko Parać, Hrvoje Raguž, Matilda Gegović, Lukrecija Levak and Danijel Marinić \\ Department of Ophthalmology, Poliklinika Knezovic Zagreb, Croatia
}

*Corresponding author: Igor Knezović, Department of Ophthalmology, University of Zagreb, Croatia, Balkans

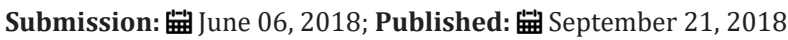

\begin{abstract}
Purpose: To evaluate the results after CLE and bilateral implantation of extended-range-of-vision

presbyopia-correcting lenses in terms of visual acuity at different distances, photic phenomena and subjective patient satisfaction with the visual outcome.
\end{abstract}

Setting: Eye Institute "Poliklinika Knezović”, Zagreb, Croatia

Design: Prospective study

Methods: Moderately motivated patients with adequate visual requirements and reasonable postoperative expectations had CLE and bilateral implantation of extended-range-of-vision presbyopia-correcting IOL (Tecnis, Symfony) with the same surgical procedure and the same surgeon performing the surgery. Postoperative distance, intermediate and near visual acuity were measured 1, 3 and 6 months postoperatively. On the last clinical visit, patients were given a questionnaire to complete, grading satisfaction with the surgery outcome.

Results: The study comprised 30 patients (60 eyes; mean age $62+/-10$ ) of which high percentage had good and satisfying visual acquity at all distances, acceptable number of photic phenomena (reported by less than $10 \%$ of patients) and high percentage of subjectively satisfied patients.

Conclusion: After bilateral implantation of extended-range-of-vision IOL binocular non-corrected distance, intermediate and near visual acuity improvement was achieved along with high overall patient satisfaction, spectacle independence for majority of patients most of the time and relatively small number of photic phenomena.

\section{Introduction}

Monofocal intraocular lenses (IOL) have been providing excellent distance vision in last few decades after cataract surgery [1]. Such patients still required spectacle correction for reading and intermediate distance, such as computer work. In the past decade, multifocal IOLs have been designed to improve spectacle independence after the cataract surgery [2]. At the same time, CLE has become increasingly accepted as an adequate alternative to other refractive procedures [3]. Controversial at first, CLE used to be reserved for patients with high myopia that could not be managed with laser in situ keratomileusis (LASIK) or photorefractive keratectomy (PRK) or even better for the patients with high hyperopia due to the fewer treatment modalities and the lesser risk of postoperative retinal detachment compared with highly myopic eyes.
Along with the improvement of surgical techniques and technological advancements in IOL design and production, refractive lens exchange (RLE) increases its percentage in general number of all refractive procedures. A new promising design of IOL has recently been introduced, based on generation of extendedrange-of-vision resulting in satisfactory visual outcome while minimizing unwanted photic phenomena and visual disturbances $[4,5]$. TECNIS Symfony Intraocular lenses (IOL) implanted in this study uses echelettes, a type of diffraction grating, to extend the IOL's focus range. At the same time, it corrects chromatic aberration to enhance contrast sensitivity [6]. The aim of this study was to evaluate the results after bilateral implantation of extended-rangeof-vision presbyopia-correcting lenses in terms of visual acuity at different distances, photic phenomena and subjective patient satisfaction with the visual outcome [7]. 


\section{Patients and Methods}

\section{Study design and patient selection}

This prospective case series study comprised 30 patients (60 eyes) of a mean age of $62+/-10$. Patients selected in a study included moderately motivated individuals with adequate visual requirements and reasonable postoperative expectations. Twentytwo (44 eyes) patients had low to moderate hyperopia (between $+1.00 \mathrm{D}$ and $+5.00 \mathrm{D}$ ), 4 (8 eyes) were highly hyperopic [more than $+5.00 \mathrm{D}$ ] and 4 patients (8 eyes) had moderate to high myopia (in a range from $-2.75 \mathrm{D}$ to $-7.00 \mathrm{D}$ ). Nine eyes with significant topographic astigmatism required implantation of toric IOL. Exclusion criteria were other eye conditions such as glaucoma, maculopathy, amblyopia, squint, abnormal binocular vision, visual field defects and abnormal preoperative parameters measured in preoperative assessment.

\section{Preoperative assessment}

Preoperative assessment included determining visual acuity (distance, intermediate and near), ocular surface assessment, determining eye dominance, optical biometry (measuring axial lenght, white-to-white measurement, IOL calculation (Nidek, AL scan, Optical biometer), pupil size measurement in different light conditions (photopic, mesopic and scotopic; 40 lux, 4 lux and 0.04 lux respectively), corneal topography and aberrometry (CSO Antares Topographer), tomography (Allegro Oculyzer, Medical Vision AG), anterior segment OCT, advanced tear film analysis, Meibography (CSO Antares Topographer), Tear Break-up Time Test (TBUT), Lissamine green, and Schirmer I test.

\section{Surgical technique}

All performed surgeries were done in a topical anesthesia by a standard sutureless phacoemulsification technique. Mydriasis was induced using tropicamide $1.0 \%$ and phenylephrinhydrochlorid $10.0 \%$. A clear cornea microincision

$\mathrm{n}$ of $2.2 \mathrm{~mm}$ was located on a steep meridian. Surgical procedure was performed targeting mini-monovision on the non-dominant eye (-0.50 Dsph) and emmetropia on the dominant one that was operated one week after the first one [8,9]. The SRK-T formula was used in IOL power calculation for all eyes with axial length longer than $22.0 \mathrm{~mm}$. The Holladay I formula was used for all the other eyes [10]. All patients had bilateral implantation of extended-range-ofvision presbyopia-correcting IOL (Tecnis, Symfony) with the same surgical procedure and the same surgeon performing the surgery.

\section{Outcome measurements}

Postoperative distance, intermediate and near vision were measured 1, 3 and 6 months postoperatively.

Patients completed a questionnaire grading subjective satisfaction with the surgery outcome during the last follow-up visit [11]. Distance visual acuity was taken on a standard Nidek SC-2000 chart under photopic conditions and 100\% contrast. Near and intermediate vision were measured with Sloan EDTRS charts under the same conditions.
The questionnaire compiled by our team included following questions:

A. How would you grade your distance vision on a scale 1 (poor) -10 (excellent)?

B. How would you grade your intermediate distance vision (computer) on a scale 1 (poor) -10 (excellent)?

C. How would you grade your near distance vision (reading) on a scale 1 (poor) -10 (excellent)?

D. Do you see haloes, starbursts or glare around light sources at night? $(\mathrm{Y} / \mathrm{N})$

E. Do you have difficulties reading traffic signs because of too much light [flashes]? (Y/N)

F. How would you grade your night vision? (1 (poor) -10 (excellent))

G. How painful was your postoperative recovery? (1 (extremely painful) - 10 (painless))

H. Would you undergo the procedure again? $(\mathrm{Y} / \mathrm{N})$

I. Would you recommend the procedure to a friend or an acquaintance? $(\mathrm{Y} / \mathrm{N})$

J. How would you grade your overall satisfaction after the procedure on a scale 1-10?

\section{Results}

\section{Visual outcomes}

At the last clinical visit, 6 months after surgery, mean binocular uncorrected distance visual acuity (UDVA) was $0.98+/-0.18$, mean binocular uncorrected intermediate visual acuity (UIVA) was $0.98+/-0.12$ and mean uncorrected near visual acuity (UNVA) was $0.93+/-0.14$, regardless of the amount and nature of pre-existing refractive error. Binocular distance, intermediate and near visual acuity distribution at 1, 3- and 6-months postoperative follow-up visits are shown in Figure 1-3.

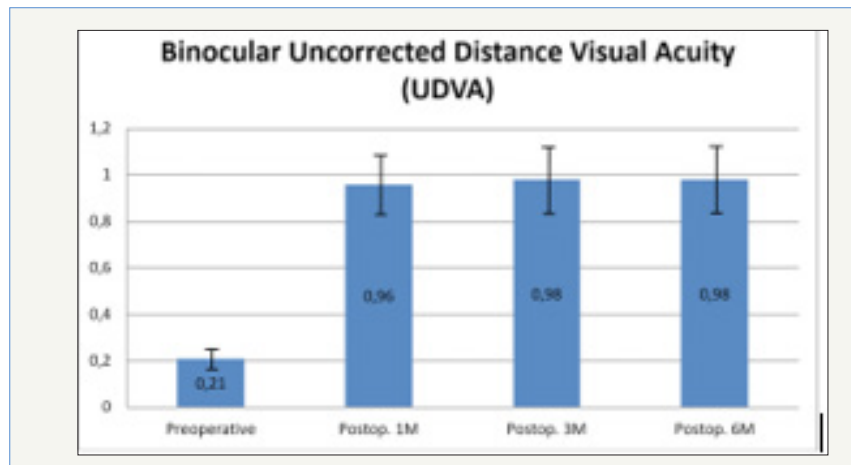

Figure 1: Binocular uncorrected distance visual acuity (UDVA).

\section{Photic phenomena and patient satisfaction}

In a survey given to the patients, slightly less than $10 \%$ of patients have reported some photic phenomena (halos, night glare and starbursts) with distribution shown in Figure 4. 


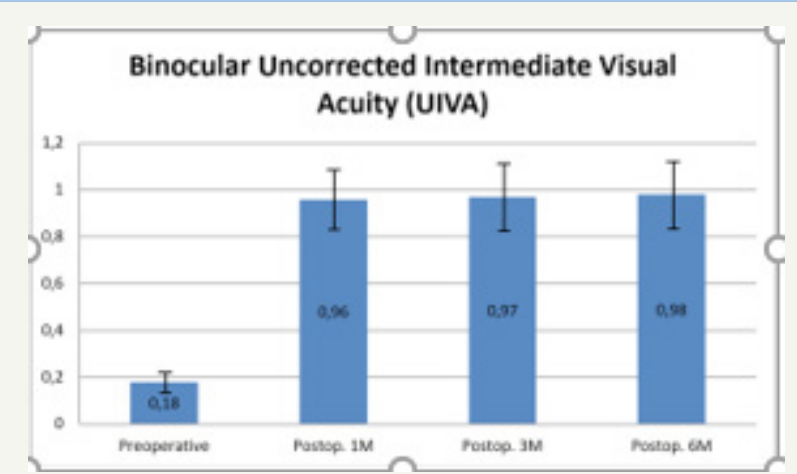

Figure 2: Binocular uncorrected intermediate visual acuity (UIVA).

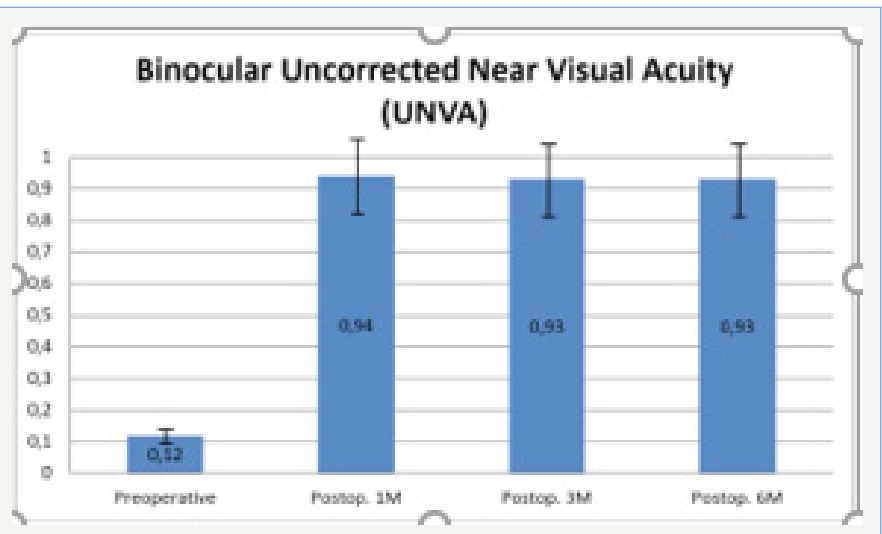

Figure 3: Binocular uncorrected near visual acuity (UNVA).

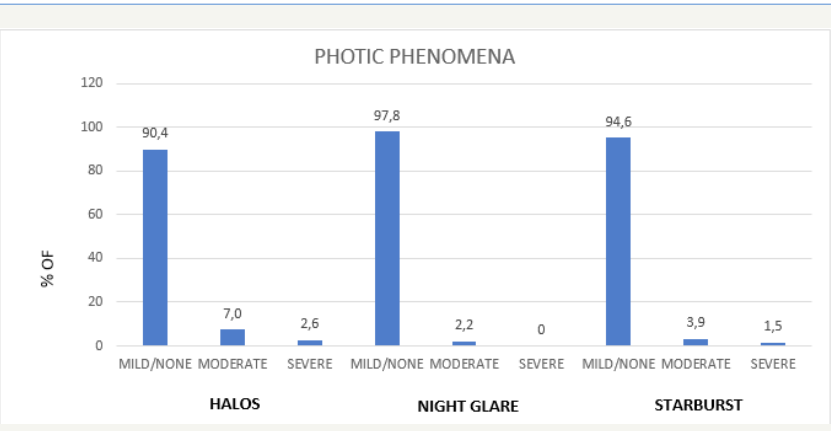

Figure 4: Patient high subjective overall satisfaction was achieved with a mean grade of 9.1 on a scale 1-10.

\section{Discussion}

Cataract surgery has rapidly evolved into a refractive procedure with patients increasing demands for unaided distance, intermediate and near vision. While diffractive multifocal IOL provide two distinct foci for distance and near, intermediate visual acuity is compromised. On the other side, low add multifocal IOLs improve intermediate vision, but compromise near visual acuity. The idea with the new generation of extended-range-of-vision IOLs was to overcome these problems. The most important aspects of refractive surgery are accuracy, stability, safety and quality of vision. In terms of accuracy, our results of refractive lens exchange have shown less than +-0.25 D deviation yielding mean binocular uncorrected distance visual acuity (UDVA) of 0.98 , mean binocular uncorrected intermediate visual acuity (UIVA) of 0.98 and mean uncorrected near visual acuity (UNVA) of 0.93 at 6-month clinical visit, regardless of the amount and nature of pre-existing refractive error.

These results correspond to results achieved in the multicentric Concerto study [12], showing UIVA results superior to the results achieved in numerous studies reporting intermediate visual acuity results with implanted bifocal and trifocal IOLs [13-16]. No significant difference was shown between visual acuities at all distances for 1 month, 3 months and 6 months follow-up visits.

Regarding stability, RLE probably represents the most stable refractive procedure, with +/- 0.02 D per year reported over a 9-year follow-up period [17-20]. In terms of safety, opinions still differ, but RLE has passed a long way from an "idea before its time" to the "idea whose time has come" for an increasing number of ophthalmic surgeons, with care taken of the ethics and careful patient selection, detailed preoperative assessment, minutious surgical technique and adequate postoperative care. In terms of quality of vision, we were primarily interested in a subjective and objective parameters of vision quality of our patients after the implantation of Tecnis Symfony IOL to deliver the best possible care to our patients that were eager to reach the largest possible amount of spectacle independence. The achieved results were satisfactory for both our patients and we and consistent with previously reported results by other authors using the same or similar IOL [21].

\section{References}

1. Calladine D, Evans JR, Shah S, Leyland M (2015) Multifocal versus monofocal intraocular lenses after cataract extraction. Sao Paulo Med J 133(1): 68.

2. De Silva SR, Evans JR, Kirthi V, Ziaei M, Leyland M (2016) Multifocal versus monofocal intraocular lenses after cataract extraction. Cochrane Database of Systematic Reviews.

3. Schallhorn SC, Teenan D, Venter JA, Schallhorn JM, Hettinger KA, et al. (2017) Monovision LASIK versus presbyopia-correcting IOLs: comparison of clinical and patient-reported outcomes. J Refract Surg 33(11): 749-758.

4. Schallhorn SC, Schallhorn JM, Pelouskova M, Venter JA, Hettinger KA, et al. (2017) Refractive lens exchange in younger and older presbyopes: comparison of complication rates, 3 months clinical and patientreported outcomes. Clin Ophthalmol 11: 1569-1581.

5. Ferreira TB, Pinheiro J, Zabala L, Ribeiro FJ (2018) Comparative analysis of clinical outcomes of a monofocal and an extended-range-of-vision intraocular lens in eyes with previous myopic laser in situ keratomileusis. J Cataract Refract Surg 44(2): 149-155.

6. Pedrotti E, Carones F, Aiello F, Mastropasqua R, Bruni, E et al. (2018) Comparative analysis of visual outcomes with 4 intraocular lenses: Monofocal, multifocal, and extended range of vision. J Cataract Refract Surg 44(2): 156-167.

7. Hogarty DT, Russell DJ, Ward BM, Dewhurst N, Burt P (2018) Comparing visual acuity, range of vision and spectacle independence in the extended range of vision and monofocal intraocular lens. Clin Exp Ophthalmol.

8. Ito M, Shimizu K, Niida T, Amano R, Ishikawa H (2014) Binocular function in patients with pseudophakic monovision. J Cataract Refract Surg 40(8): 1349-1354. 
9. Finkelman YM, Ng JQ, Barrett GD (2009) Patient satisfaction and visual function after pseudophakic monovision. J Cataract Refract Surg 35(6): 998-1002.

10. Savini G (2015) Accuracy of the refractive prediction determined by multiple currently available intraocular lens power calculation formulas in small eyes. Am J Ophthalmol 160(1): 202-203.

11. Kaymak H, Höhn F, Breyer DR, Hagen P, Klabe K, et al. (2016) Functional results 3 months after implantation of an "extended range of vision" intraocular lens. Klin Monbl Augenheilkd 233(8): 923-927.

12. Cochener B, Concerto Study Group (2016) Clinical outcomes of a new extended range of vision intraocular lens: International Multicenter Concerto Study. J Cataract Refract Surg 42(9): 1268-1275.

13. Lubiński W, Gronkowska SJ, Podborączyńska JK (2014) Clinical outcomes after cataract surgery with implantation of the Tecnis ZMB00 multifocal intraocular lens. Med Sci Monit 15(20): 1220-1226.

14. Attia MSA, Auffarth GU, Kretz FTA, Tandogan T, Rabsilber TM, et al. (2017) Clinical evaluation of an extended depth of focus Intraocular lens with the salzburg reading desk. J Refract Surg 33(10): 664-669.

15. Cillino G, Casuccio A, Pasti M, Bono V, Mencucci R, et al. (2014) Workingage cataract patients: visual results, reading performance and quality of life with three diffractive multifocal intraocular lenses. Ophthalmology 121(1): 34-44.
16. Cochener B (2016) Prospective clinical comparison of patient outcomes following implantation of trifocal or bifocal Intraocular lenses. J Refract Surg 32(3): 146-151.

17. Dúbravská Z, Rozsíval P (2007) Refractive lensectomy-long-term results. Cesk Slov Oftalmol 63(1): 28-35.

18. Lee KH, Lee JH (1996) Long-term results of clear lens extraction for severe myopia. J Cataract Refract Surg 22(10): 1411-1415.

19. Rosen E, Alió JL, Dick HB, Dell S, Slade S (2016) Efficacy and safety of multifocal intraocular lenses following cataract and refractive lensexchange: Metaanalysis of peer-reviewed publications. J Cataract Refract Surg 42(2): 310-328.

20. Alió JL, Grzybowski A, Romaniuk D (2014) Refractive lens exchange in modern practice: when and when not to do it? Eye Vis (Lond) 10:1-10.

21. Hiratsuka Y, Yamada M, Akune Y, Murakami A, Okada AA, et al. (2014) Assessment of vision-related quality of life among patients with cataracts and the outcomes of cataract surgery using a newly developed visual function questionnaire: the VFQ-J11. Jpn J Ophthalmol 58(5): 415-422.
(C) (P) Creative Commons Attribution 4.0 International License

For possible submissions Click Here
Submit Article

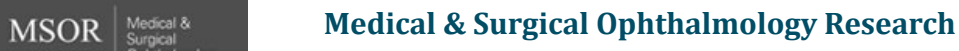 Benefits of Publishing with us}

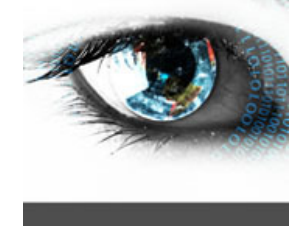

- High-level peer review and editorial services

- Freely accessible online immediately upon publication

- Authors retain the copyright to their work

- Licensing it under a Creative Commons license

- Visibility through different online platforms 